\title{
EXTRAÇÃO DO ÓLEO, PRODUÇÃO E CARACTERIZAÇÃO DE PROPRIEDADES FÍSICAS DO BIODIESEL DE SEMENTES DE MARACUJÁ - PASSIFLORAEDULIS
}

\author{
Julia Domingues ${ }^{1}$ \\ IvenioMoreira da Silva ${ }^{2}$ \\ Ednilton Tavares de Andrade ${ }^{3}$ \\ Fernanda Ferreira ${ }^{4}$
}

\begin{abstract}
Resumo: O óleo extraído das sementes de maracujá (Passiflora edulis) pode ser utilizado para diversos fins industriais, sendo aplicado na indústria de cosméticos, fabricação de tintas, sabões e outras. Mediante o incentivo dado à produção de biocombustíveis e o estudo das variadas fontes de matéria-prima nos últimos anos, o biodiesel produzido a partir do óleo extraído das sementes de maracujá, apresenta-se como viável alternativa em regiões produtoras. Para o presente estudo, as sementes de maracujá foram lavadas para retiradas dos resíduos de poupa e posteriormente secas à sombra. Elas foram prensadas mecanicamente através de prensa Ecirtec MP-40, e o óleo obtido, que possui a massa específica de $924,29 \mathrm{~kg} \cdot \mathrm{m}^{-3} \mathrm{e}$ a viscosidade cinemática de $27,918 \mathrm{~mm}^{2} . \mathrm{s}^{-1}$, passou pelos processos de filtragem e degomagem ácida com ácido fosfório a 5\%. A produção do biodiesel foi feita por rota etílica e com o uso do $\mathrm{NaOH}$ como catalizador. Foram utilizados um agitador mecânico e um ultrasson no processo. Posteriormente, foram estudadas propriedades físicas como a viscosidade cinemática do combustível, onde obteve-se um valor de $4,197 \mathrm{~mm}^{2} . \mathrm{s}^{-1}$.
\end{abstract}

Palavras-Chave: Biodiesel, Maracujá, Degomagem.

\section{EXTRACTION OF OIL, PRODUCTION AND CHARACTERIZATION OF PHYSICAL PROPERTIES OF BIODIESEL FROM SEEDS OF PASSIONFRUIT - PASSIFLORAEDULIS}

\begin{abstract}
The oil extracted from the seeds of passion fruit (Passifloraedulis) can be used for a lot of industrial purposes, being applied in cosmetics, paints, soaps and others. Through the encouragement of biofuels production and the study of different sources of raw materials in recent years, the biodiesel produced from the oil extracted from the seeds of passion fruit, presents itself as viable alternative for producing regions. For the present study, the passion fruit seeds were washed in order to remove the leavings of fruit and subsequently dried at shadow. They were mechanically pressed by Ecirtec MP-40 and the final oil, which has a density of $924,29 \mathrm{~kg} \cdot \mathrm{m}^{-3}$ and a kinematic viscosity of $27,918 \mathrm{~mm}^{2} . \mathrm{s}^{-1}$ was subjected to filtration process and phosphoric acid degumming 5\%. The production of biodiesel was performed by ethyl route using $\mathrm{NaOH}$ as a catalyst. We used a mechanical stirrer and an ultrasound in the process. Thereafter, physical properties were evaluated as the kinematic viscosity of the fuel, which were $4,197 \mathrm{~mm}^{2} \cdot \mathrm{s}^{-1}$.
\end{abstract}

Keywords:Biodiesel, Passionfruit, Degumming.

\footnotetext{
${ }^{1}$ UFF; 21 80915251; juliadomingues@gmail.com

${ }^{2}$ UFF; 21 88838262; ivenio@vm.uff.br

${ }^{3}$ UFF; 21 26295395; ednilton@vm.uff.br

${ }^{4}$ UFF, fernandaferreira@id.uff.br
} 


\section{1 - INTRODUÇÃO}

O óleo extraído das sementes de maracujá (Passiflora edulis) pode ser utilizado para diversos fins industriais, sendo aplicado na indústria de cosméticos, fabricação de tintas, sabões e outras. Mediante o incentivo dado à produção de biocombustíveis e ao estudo das variadas fontes de matéria-prima nos últimos anos, o biodiesel produzido a partir do óleo extraído das sementes de maracujá, apresenta-se como viável alternativa em regiões produtoras.

Nos últimos anos, diversas fontes de matérias primas para a produção de biodiesel estão sendo estudadas, e o óleo extraído de sementes de espécies oleaginosas tem recebido destaque. As culturas oleaginosas têm recebido especial atenção no âmbito acadêmico e industrial, pois são matérias-primas potencialmente promissoras na síntese de diversos materiais, a exemplo do biodiesel, materiais poliméricos, lubrificantes, resinas e ceras. Além disso, apresentam-se como uma proposta de sustentabilidade, por serem um recurso renovável que podem reduzir ou substituir os derivados do petróleo (O’Brien, 2009)

Todos os óleos vegetais, enquadrados na categoria de triglicerídeos, podem ser transformados em biodiesel, e o rendimento em óleo vegetal das oleaginosas varia de acordo com a espécie, bem como o potencial de cultivo no país (Soareset al., 2011).

Apesar do otimismo é necessário considerar as metas da produção nacional e resolver as questões que tem sido levantadas em relação às ares de preservação e a migração de áreas de produção de grãos para a agricultura de energia, bem como, aumentar a abrangência no mercado externo sem incorrer em danos ambientais (Andrade et al., 2009).

A cultura do maracujá, por sua vez, vem ocupando um lugar de destaque na fruticultura tropical, um segmento que se expandiu como um todo nos últimos 30 anos. Considerada como uma alternativa agrícola interessante para a pequena propriedade cafeeira, é a fruteira que mais tem atraído os produtores. Representa uma boa opção entre as frutas por oferecer o mais rápido retorno econômico, bem como a oportunidade de uma receita distribuída pela maior parte do ano (Meletti, 2011).

A composição química do óleo de maracujá e suas propriedades físicoquímicas estão descritas nas tabelas 1 e 2, respectivamente, conforme Conceição et al.(2011).

Tabela 1. Composição química do óleo de maracujá.

\begin{tabular}{|c|c|}
\hline Ácido Graxo & $\begin{array}{c}\text { Concentração } \\
(\%)\end{array}$ \\
\hline $\begin{array}{l}\text { Mirístico } \\
\left.\left(\mathrm{CH}_{2}\right)_{12}-\mathrm{COOH}\right)\end{array}$ & 0,1 \\
\hline $\begin{array}{l}\text { Palmítico }\left(\mathrm{CH}_{3-}^{-}\right. \\
\left.\left(\mathrm{CH}_{2}\right)_{14}-\mathrm{COOH}\right)\end{array}$ & 10,9 \\
\hline $\begin{array}{l}\text { Palmilotéico } \quad\left(\mathrm{CH}_{3^{-}}\right. \\
\left(\mathrm{CH}_{2}\right)_{5}-\mathrm{CH}-\mathrm{CH}-\left(\mathrm{CH}_{2}\right)_{7^{-}} \\
\mathrm{COOH})\end{array}$ & 0,1 \\
\hline $\begin{array}{l}\text { Esteárico } \\
\left.\left(\mathrm{CH}_{2}\right)_{16-} \mathrm{COOH}\right)\end{array}$ & 2,8 \\
\hline $\begin{array}{l}\text { Oléico } \quad\left(\mathrm{CH}_{3^{-}}\left(\mathrm{CH}_{2}\right)_{7^{-}}\right. \\
\mathrm{CH}=\mathrm{CH}-\left(\mathrm{CH}_{2}\right)_{7^{-}} \\
\mathrm{COOH})\end{array}$ & 17,3 \\
\hline $\begin{array}{l}\text { Linoléico }\left(\mathrm{CH}_{3}-\left(\mathrm{CH}_{2}\right)_{3-}^{-}\right. \\
\left(\mathrm{CH}_{2}-\mathrm{CH}=\mathrm{CH}\right)_{2^{-}} \\
\left(\mathrm{CH}_{2}\right)_{7}-(\mathrm{COOH})\end{array}$ & 68,1 \\
\hline $\begin{array}{l}\text { Linolênico } \quad\left(\mathrm{CH}_{3^{-}}\right. \\
\left(\mathrm{CH}_{2}\right)_{3}-\left(\mathrm{CH}_{2^{-}}\right. \\
\mathrm{CH}=\mathrm{CH})_{3^{-}}\left(\mathrm{CH}_{2}\right)_{7^{-}} \\
(\mathrm{COOH})\end{array}$ & 0,3 \\
\hline
\end{tabular}


Tabela 2. Propriedades físicoquímica do óleo de maracujá.

\begin{tabular}{|c|c|}
\hline Propriedades & Óleo de Maracujá \\
\hline $\begin{array}{c}\text { Índice de Acidez, mg } \\
\text { KOH. } \mathrm{g}^{-1}\end{array}$ & 2,0 \\
\hline $\begin{array}{c}\text { Índice de } \\
\text { Saponificação, mg } \\
\text { KOH.g }\end{array}$ & 185,0 \\
\hline $\begin{array}{l}\text { Índice de Matéria, } \\
\text { Insaponificação, \%. }\end{array}$ & 0,4 \\
\hline $\begin{array}{l}\text { Índice de Peróxido, } \\
\text { mEq } \mathrm{O}_{2} \mathrm{~kg}^{-1} \text {. }\end{array}$ & 8,0 \\
\hline $\begin{array}{c}\text { Viscosidade } \\
\text { Cinemática, } \mathrm{mm}^{2} \cdot \mathrm{s}^{-1} \text {. }\end{array}$ & 30,4 \\
\hline $\begin{array}{c}\text { Estabilidade } \\
\text { Oxidativa, h. } 110^{\circ} \mathrm{C}^{-1} \text {. }\end{array}$ & 13,6 \\
\hline Umidade, $\%$. & 1,0 \\
\hline Índice de lodo. & 133,8 \\
\hline
\end{tabular}

Lopes et al.(2010) verificaram o teor de lipídeos obtendo valores de 16,7 a

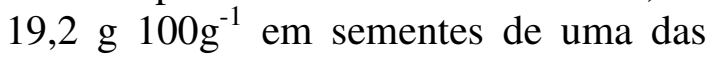
variedades de maracujá estudadas. Contudo, o óleo extraído, precisa ser submetido a processos que permitam seu enquadramento como combustível. Esses processos vão da quebra dos triglicerídeos que são de cadeias longas à caracterização do produto resultante. A transesterificação é o processo em que o óleo vegetal, triacilglicerídeo, reage com um álcool na presença de uma base ou ácido forte, produzindo uma mistura de ésteres de ácidos graxos e glicerol.

Conforme Knothe (2005), as propriedades do biodiesel que são determinadas através da estrutura de seus ésteres de ácidos graxos incluem a qualidade de ignição, ponto de fulgor, ponto de fluidez, estabilidade oxidativa, viscosidade e lubricidade.

Misturas de biodiesel ao óleo diesel foram estudadas por Alptekin\&Canakci (2008) sendo verificado o aumento da viscosidade e da massa específica das mesmas em relação à proporção de biodiesel adicionado.
A viscosidade de alguns combustíveis de petróleo é importante para estimar uma ótima estocagem, manuseio e condições de operação. Deste modo, a medição precisa da viscosidade é essencial para a especificação de muitos produtos. Tal propriedade afeta a atomização de um combustível e sua injeção na câmara de combustão, desse modo formando depósitos no motor.

Machado (2008) cita que a massa especifica de um combustível para motores diesel é uma propriedade fundamental, pois a bomba injetora e os injetores são construídos para dosar volumes pré-determinados de um combustível padrão, enquanto que o fator determinante na câmara de combustão é a relação entre massas de ar e de combustível.

Em função do descrito anteriormente, esta pesquisa teve como objetivo a extração do óleo de Sementes de Maracujá - Passiflora edulis, seguido da produção do biodiesel e da caracterização das propriedades físicoquímicas Viscosidade Cinemática e Massa Específica.

\section{2 - MATERIAL E MÉTODOS}

Para o presente estudo as sementes de maracujá foram adquiridas na Indústria de Sucos Imbiara Ltda. Elas foram lavadas para retiradas dos resíduos de polpa e posteriormente secas à sombra. O processo de secagem foi complementado com o uso de câmara desidratadora com ventilação forçada. As sementes foram prensadas mecanicamente através de prensa Ecirtec MP-40, e o óleo obtido passou pelos processos de filtragem e degomagem ácida a $5 \%$, onde foi colocado $5 \%$ de ácido fosfórico ao óleo de maracujá aquecido à $65^{\circ} \mathrm{C}$, seguido de uma agitação mecânica de 30 minutos. Para o processo de transesterificação, foram utilizados $50 \%$ de etanol e $2 \%$ de hidróxido de sódio (NAOH). Para ocorrer a reação, os produtos foram submetidos a 
uma agitação mecânica de 20 minutos e mais 30 minutos no ultrassom. Ao fim, obteve-se o biodiesel de maracujá e a glicerina.

O estudoda massa específica foi realizado mediante o uso do método do Picnômetro para a realização das medições, baseando-se na norma Nie_Dimel-039, do INMETRO.

A determinação da viscosidade cinemática foi realizada conforme as normas NBR 10441 E ASTM D 445. Foi utilizado viscosímetro Cannon Fenske, capilar $100\left(\mathrm{~K}=0,01512 \mathrm{~mm}^{2} . \mathrm{s}^{-2}\right)$ e banho termostático a $40^{\circ} \mathrm{C}$. O valor de viscosidade foi obtido multiplicando-se o tempo pela constante de calibração $(\mathrm{K})$ do viscosímetro.

\section{3 - RESULTADOS E DISCUSSÃO}

No processo de prensagem (Figura 1 e 2), obteve-se um rendimento de 16,02 $\%$, onde foram obtidos sete litros de óleobruto (Figura 3).Após afiltragem (Figura 4) e o seu acondicionamento em frascos âmbar, realizou-se na mesma semana a caracterização de propriedades físico-químicas. Obteve-se os valores $924,29 \mathrm{~kg} \cdot \mathrm{m}^{-3} \mathrm{e} 27,918 \mathrm{~mm}^{2} . \mathrm{s}^{-1}$ referentes à Massa Específica e a Viscosidade Cinemática do óleo, respectivamente (Figuras 5 e 6 ).

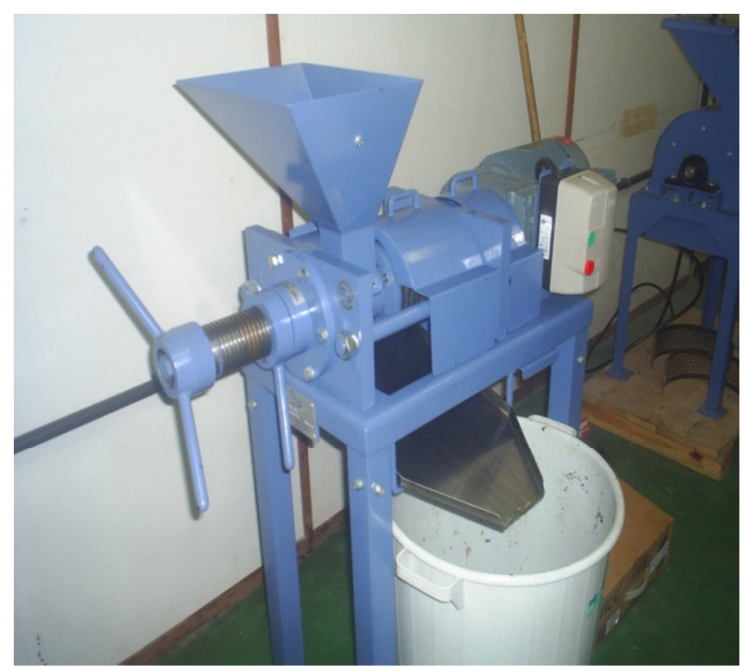

Figura 1 - Prensagem das sementes. Fonte: Arquivo pessoal

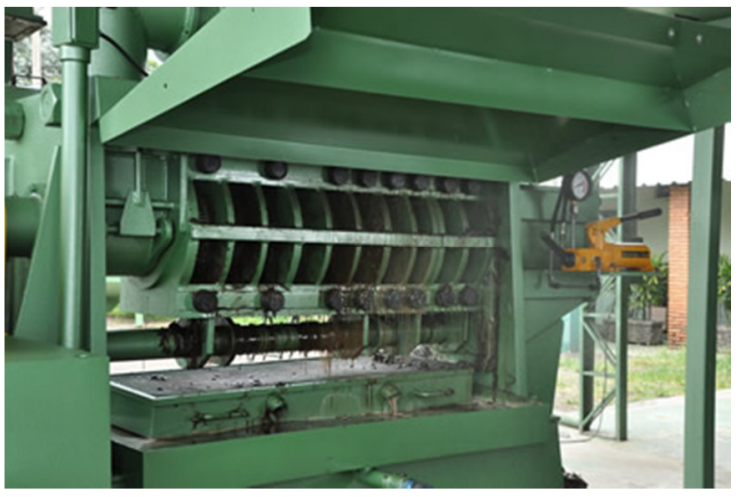

Figura 2 - Extração do óleo de maracujá. Fonte: Arquivo pessoal.

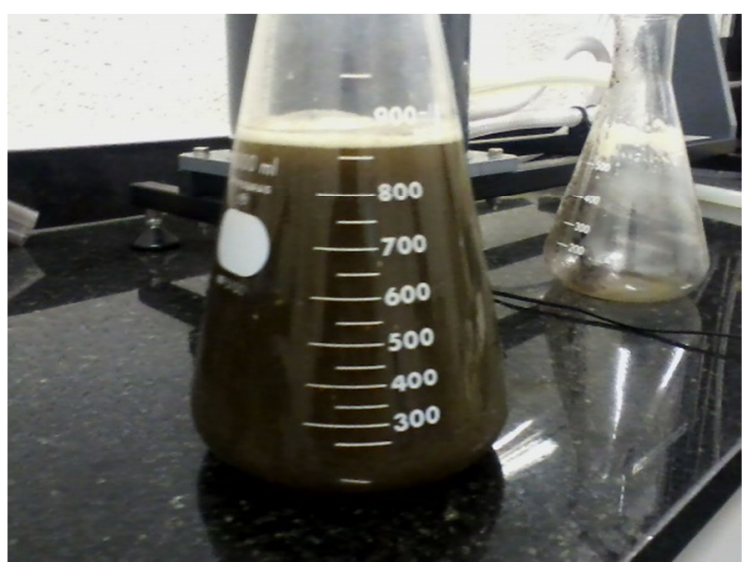

Figura 3 - Óleo bruto de maracujá. Fonte: Arquivo pessoal.

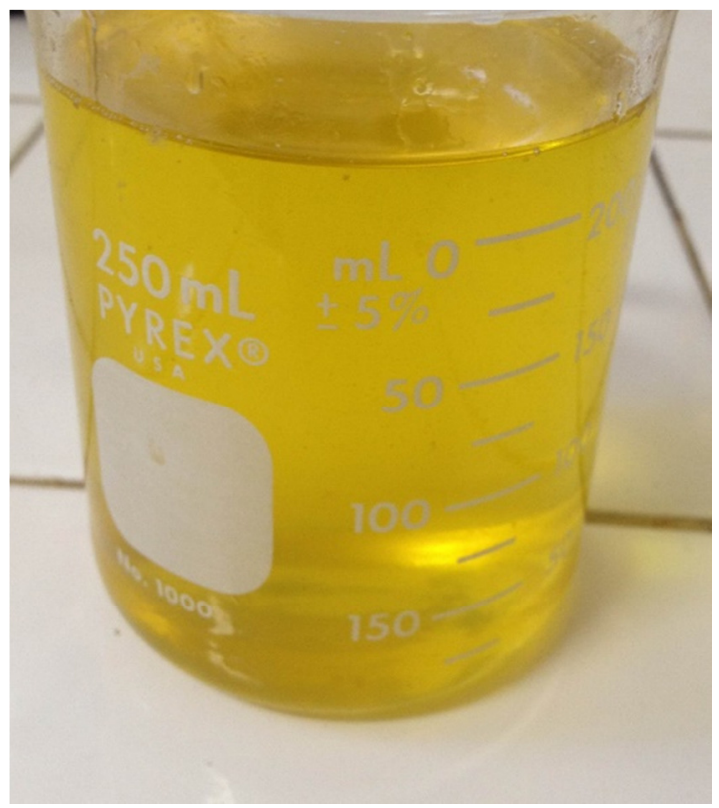

Figura 4 - Óleo filtrado de Maracujá. Fonte: Arquivo pessoal. 


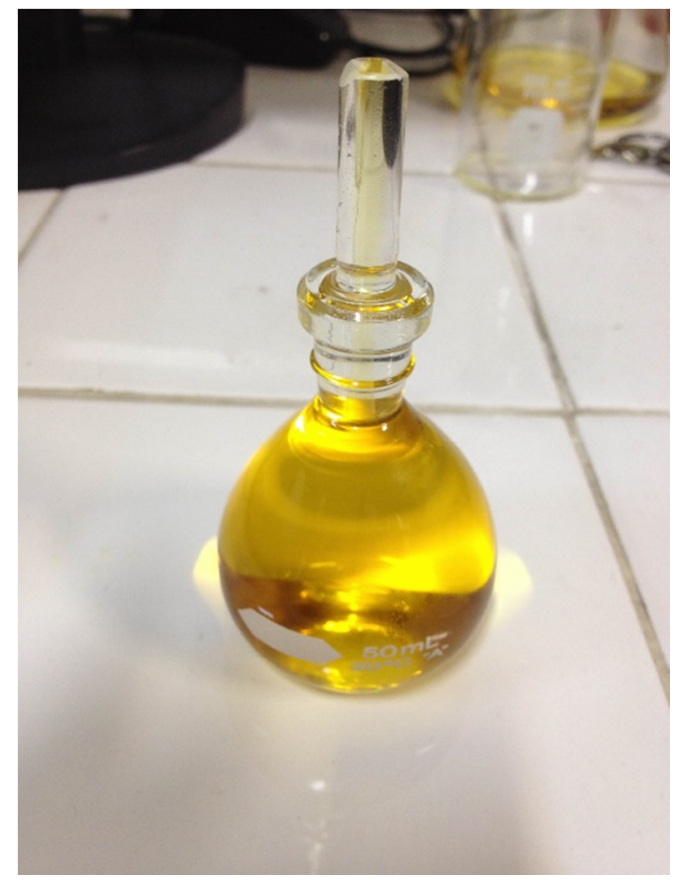

Figura 5 - Massa específica. Fonte: Arquivo pessoal.

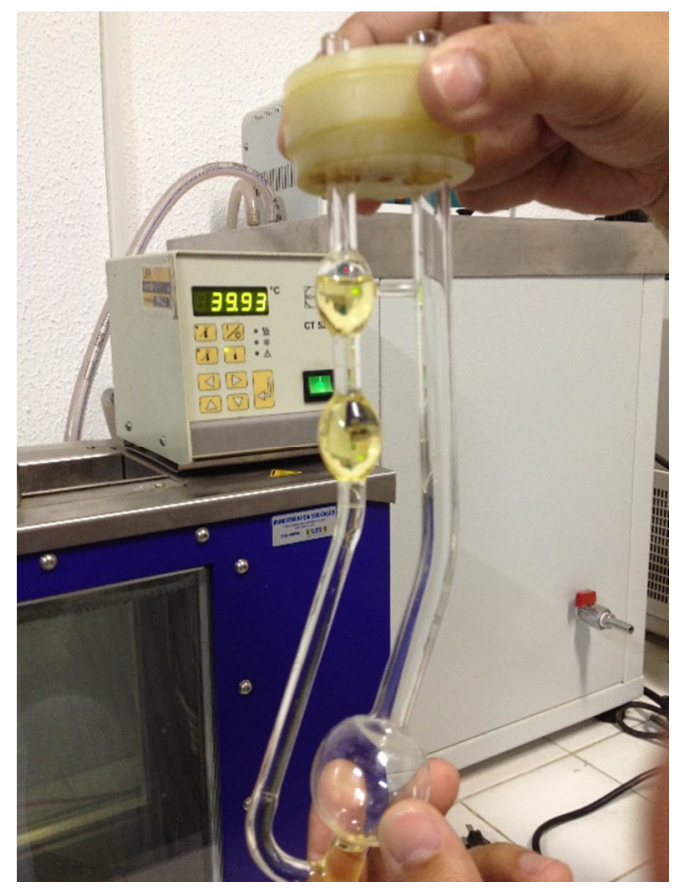

Figura 6 - Viscosímetro. Fonte: Arquivo pessoal.

Foram encontradas dificuldades na produção do biodiesel do óleo de maracujá devido, principalmente, à alta viscosidade do óleo e o seu baixo índice de pureza. Após a realização de diversos testes os resultados obtidos não foram satisfatórios, observando-se o endurecimento do material após a reação de transesterificação e a não separação do glicerol (Figura 7). Tal comportamento pode ser explicado pela presença de fosfatídeos e impurezas no óleo. Assim, tornou-se necessário realizar novos ensaios para que o óleo fosse submetido ao processo de degomagem ácida (Figura $8)$.

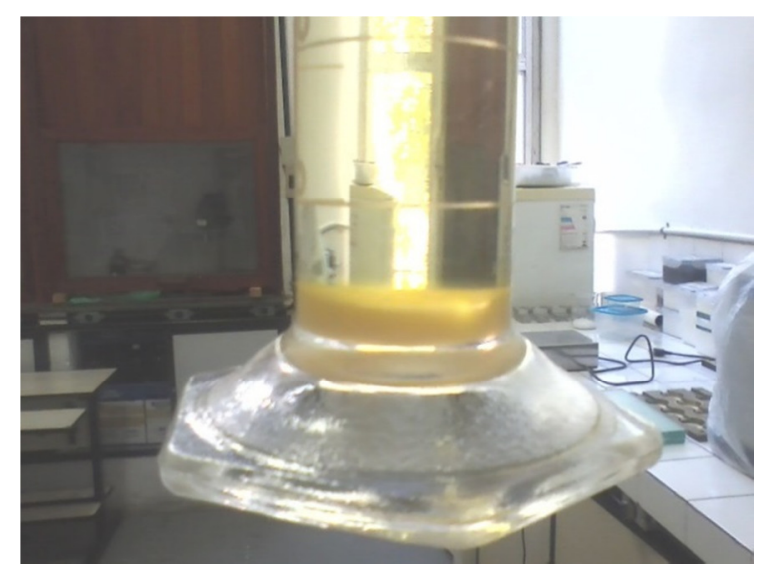

Figura 7 - Transesterificação Incompleta. Fonte: Arquivo pessoal.

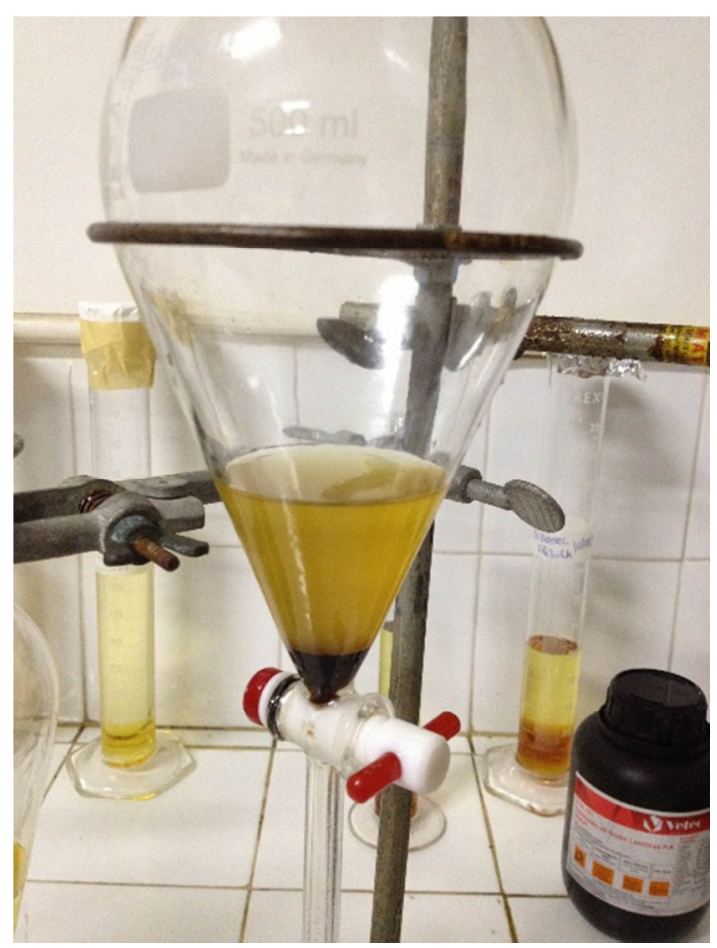

Figura 8 - Degomagem Ácida. Fonte: Arquivo pessoa.

Após a reação de transesterificação, verificou-se que utilizando $50 \mathrm{ml}$ de óleo, obteve-se 17,2 ml de glicerina (Figura 9). Posteriormente, foram estudadas propriedades físicas do combustível, onde obteve-se um valor de $4,197 \mathrm{~mm}^{2} . \mathrm{s}^{-1}$ para a viscosidade cinemática. 


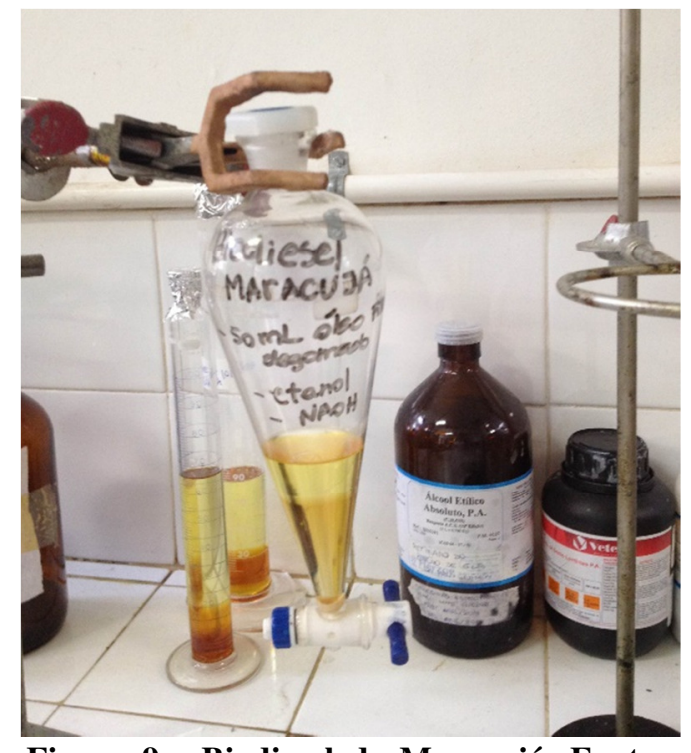

Figura 9 - Biodiesel de Maracujá. Fonte: Arquivo pessoal.

\section{4 - CONCLUSÕES}

O processo de prensagem à frio das sementes de maracujá precedeu-se de forma satisfatória, sendo observada a sua eficiência. Contudo, conclui-se que a eficiência desse processo está relacionada ao ajuste dos espaçadores da prensa, bem como o fluxo de sementes na entrada do equipamento.

Apesar do êxito na reação de transesterificação, o biodiesel produzido através do óleo extraído das sementes de maracujá apresentou alguns fatores negativos, dentre eles a quantidade acima do normal de glicerina gerada no processo. Além disso, o óleo de maracujá apresenta uma alta taxa de viscosidade e impureza, o que não só dificulta a reação, mas também gera a necessidade de aplicação de outros métodos como a degomagem ácida, que encarece a produção.

\section{5 - AGRADECIMENTOS}

Aos professoresIvênio Silva e Ednilton Tavares pelo tempo, apoio, orientação e incentivo dado à produção do trabalho. E aoPibic e CNPq pela bolsa concedida.

\section{6 - REFERÊNCIAS}

ABNT - Associação Brasileira de Normas Técnicas - Produtos de petróleo Determinação do ponto de névoa-ABNT NBR 11346.

ABNT - Associação Brasileira de Normas Técnicas Produto de petróleo Determinação do ponto de fluidez ABNT NBR 11349.

ALPTEKIN, E.,CANAKCI, M. Determinationofthedensityandtheviscositi esof biodiesel- diesel fuelblends. Renewable Energy 33. 2008.

CID, A. A. Identificação de Fatores Críticos na Produção de Biodiesel: Estratégia para Comercialização Internacional deste Biocombustível.Dissertação de Mestrado. Programa de Pós-Graduação em Tecnologia de Processos Químicos e Bioquímicos, Escola de Química, Universidade Federal do Rio de Janeiro. 2008.

CRIPPA, T. M. A inserção do biodiesel no Brasil: aspectos regulatórios e técnico econômico. Projeto de Fim de Curso- Departamento de Engenharia Industrial - Universidade Federal do Rio de Janeiro, 33 p., 2005.

KNOTHE, G. Dependence of biodiesel fuel properties on the structure of fatty acid alkyl esters.FuelProcessing Technology 86. 2005.

LOPES, R. M., SEVILHA, A. C., FALEIRO, F. G., SILVA, D. B., VIEIRA, R. F., COSTA, T. S. A. Estudo Comparativo do Perfil de Ácidos Graxos em Semente de Passifloras Nativas do Cerrado Brasileiro. Rev. Bras. Frutic., Jaboticabal - SP, v. 32, n. 2, p. 498-506, Junho 2010.

MACHADO, P. R. M. Ésteres combustíveis em motor de ciclo diesel sob condições de pré-aquecimento e 
variação no avanço de injeção.2008. 163 p. Tese de Doutorado - Programa De PósGraduação Em Engenharia Agrícola, Centro De Ciências Rurais, Universidade Federal de Santa Maria - 2008.

MELETTI, L. M. M. Avanços na Cultura do Maracujá no Brasil. Rev. Bras. Frutic., Jaboticabal - SP, Volume Especial, E. 083-091, Outubro 2011.

CONCEIÇÃO, 1. R. V, PANTOJA, s. S, CAVALCANTE, m. S, BASTOS, r. R. C, ROCHA FILHO, g. N, ZAMIAN, j. R. Comparação dos métodos assistidos por radiação de micro-ondas e convencional na produção de biodiesel de maracujá (Passiflora edulis). $51^{\circ}$ Congresso Brasileiro de Química - São Luiz do Maranhão, 2011.

ANDRADE,E. T.;CARVALHO,S. R. G., SOUZA,L. F.Programa do Proálcool e o Etanol no Brasil.Engevista, Vol.11, n.2, p.127-136. 2009

MONTEIRO,L. P. C., PASSOS F. B., HELD,A. V., TORBEY,B. Y.Técnicas de Crescimento da Microalga Dunaliella Salina para Produção de Biodiesel e Separação de Óleo e Biomassa Produzidos no Processo. Engevista, Vol. 13, No 2. 2011. 